\title{
Advanced Energy Design Guide for Small Hospitals and Healthcare Facilities ${ }^{a}$
}

\author{
Eric Bonnema ${ }^{1} *$, Shanti Pless ${ }^{1}$, Ian Doebber ${ }^{1}$ \\ ${ }^{1}$ National Renewable Energy Laboratory, 1617 Cole Boulevard, \\ Golden, Colorado, 80401, USA
}

\begin{abstract}
The Advanced Energy Design Guide for Small Hospitals and Healthcare Facilities (AEDG-SHC) was recently completed. It is the sixth document in a series of guides designed to achieve $30 \%$ savings over the minimum code requirements of ANSI/ASHRAE/IESNA Standard 90.1-1999. The guide [1] is available for print purchase or as a free download from $h t t p: / / w w w . a s h r a e . o r g / a e d g$ and provides user-friendly assistance and recommendations for the building design, construction, and owner communities to achieve energy savings. Included in the guide are prescriptive recommendations for quality assurance and commissioning; design of the building envelope; fenestration; lighting systems (including electric lighting and daylighting); heating, ventilation, and air-conditioning (HVAC) systems; building automation and controls; outside air (OA) treatment; and service water heating $(\mathrm{SWH})$. The guide educates, provides practical recommendations for exceeding code minimums, and provides leadership to help design teams and owners produce higher efficiency commercial buildings.
\end{abstract}

Keywords: $30 \%$ energy savings, high performance buildings, energy efficiency, Advanced Energy Design Guide, small healthcare facilities

\section{INTRODUCTION}

The Advanced Energy Design Guide for Small Hospitals and Healthcare Facilities (AEDG-SHC) is targeted to help small- to medium-sized acute care, outpatient, and inpatient buildings achieve site energy savings of at least 30\% compared to the minimum requirements of ANSI/ASHRAE/IES Standard 90.1-1999 [2]. The 30\% energy savings target is the first step toward achieving a net-zero energy building-a building that draws from outside sources less or equal energy than it generates on site from renewable energy sources annually [3]. The guide was developed in collaboration with these partnering organizations: the American Society of Heating, Refrigerating and Air-Conditioning Engineers (ASHRAE), the American Institute of Architects (AIA), the U.S. Green Building Council (USGBC), the Illuminating Engineering Society

\footnotetext{
*Corresponding author. Email: eric.bonnema@nrel.gov; Tel: +1 303 384-6185

a This article was prepared by the National Renewable Energy Laboratory, operated by the Alliance for Sustainable Energy LLC, under the funding of the U.S. Department of Energy."
} 
(IES), the U.S. Department of Energy (DOE), and the American Society for Healthcare Engineering (ASHE). The healthcare facilities covered in the scope of the guide are smaller than $90,000 \mathrm{ft}^{2}\left(8,360 \mathrm{~m}^{2}\right)$, defined as:

- $\quad$ Small acute care hospitals

- Small inpatient community hospitals

- Critical access hospitals with 25 or fewer beds

- $\quad$ Outpatient surgical facilities

- $\quad$ Freestanding birthing centers (similar to outpatient surgical centers)

- Gastrointestinal endoscopy facilities (similar to outpatient surgical centers)

- Renal dialysis centers (similar to medical office buildings)

- $\quad$ Primary care outpatient centers

- Small primary (neighborhood) outpatient facilities

- Freestanding outpatient diagnostic and treatment facilities

- Freestanding urgent care facilities

- $\quad$ Medical office buildings (larger than $20,000 \mathrm{ft}^{2}\left[1,858 \mathrm{~m}^{2}\right]$ )

Three major objectives drove the development of the guide: (1) to achieve a $30 \%$ energy savings over Standard 90.1-1999 [4]; (2) to produce a reference document for contractors, owners, and designers of small hospitals and healthcare facilities; and (3) to provide how-to assistance to contractors and designers [5]. The guide is intended to show that achieving the $30 \%$ target is not only possible, but easily achievable. Case studies show facilities around the country that have achieved and surpassed the $30 \%$ energy savings target. Best practices and cautions are also provided to demonstrate how to successfully implement the recommendations.

By specifying a target and identifying paths for different climate zones, the guide provides one example of how to meet the $30 \%$ savings target and how to build facilities that use substantially less energy than those built to meet the minimum Standard 90.11999 energy code requirements. There may be other means of achieving the target, and it is hoped that the guide generates ideas for innovation.

\section{LAYOUT AND CONTENT}

The introduction of the guide contains information about its goal and scope, as well as instructions for its use. Next the guide provides resources for those who want to understand and adopt an overall, integrated process for designing, constructing, and operating energy-efficient small hospitals and healthcare facilities. The guide presents an integrated process for achieving energy savings. It is valuable for designers and builders who want to augment and improve their practices so energy efficiency is deliberately considered at each stage of the development process, from project conception through building operation. This section concludes by addressing the details of an integrated design process. It discusses the benefits and features of integrated design, specifics about the process, and step-by-step details about the four phases of the process: predesign, design, construction, and acceptance/ occupancy/operation. 
The third section contains the climate-specific recommendation tables, a unique set of energy efficiency recommendations for each of the eight DOE climate zones in the United States. Efficiency recommendations are organized by several categories: envelope; electric lighting; daylighting; heating, ventilating, and air-conditioning (HVAC); and service water heating (SWH). The recommendations are simply one path to reach the 30\% energy savings target over Standard 90.1-1999. Other approaches may also save energy, but identifying all possible solutions is not in the scope of this guide; assurance of the savings with other approaches is left to the user. To achieve $30 \%$ energy savings, this guide assumes compliance with the more stringent of either the applicable edition of Standard 90.1 or the local code requirements in all areas not addressed in the climate-specific recommendation tables. Future editions of energy codes may have more stringent values. In these cases, the more stringent values are recommended.

Next the guide presents seven detailed case studies that illustrate techniques and methods discussed. Energy numbers are provided to benchmark these buildings against future buildings. All these case studies use some of the recommendations in the tables, but predate the publication of the guide and were not developed explicitly using those tables. Readers are encouraged to view more case studies at $h t t p: / / w w w . a s h r a e . o r g / a e d g$, and to submit their own. Case studies provide the motivation and the examples for others to follow.

The final section provides guidance about good practices for implementing the recommendations, as well as cautions to avoid known problems in energy-efficient construction. The section is divided into quality assurance and commissioning, envelope, lighting, daylighting, HVAC, SWH, and bonus savings. The bonus savings subsection includes areas for additional good practice items that, if implemented properly, should achieve savings beyond the $30 \%$ level.

The quality assurance and commissioning subsection contains specific details about commissioning and its importance in every step of the design process. The envelope subsection contains climate zone-specific information about explicit types of walls, roofs, floors, doors, insulation, infiltration, and vertical fenestration. The lighting subsection details best practices for interior finishes, specific lamp and ballast types, lighting layouts, and control strategies for specific space types. The daylighting subsection provides tips on general principles, using daylighting analysis tools, daylighting space types and layouts, building shape and orientation with respect to daylighting, window-to-wall ratios, sidelighting, toplighting, skylight construction, shading devices, photosensor specification, and photocell placement.

The HVAC subsection includes best practices for multiple-zone variable-air volume (VAV) air-handling systems, water-source (including ground-source) heat pumps, dedicated outdoor air (OA) systems, HVAC load calculations, equipment efficiencies, economizers, exhaust air energy recovery, ductwork design, duct insulation, duct sealing, exhaust air systems, system-level control strategies, filters, chilled water systems, heating water systems, and zone-level controls.

The bonus savings subsection includes good practices for lighting (exterior lighting, lamp types), process loads (medical equipment, high-performance kitchen and laundry equipment), renewable energy (photovoltaic and solar hot water systems, wind turbines), 
combined heat and power, additional HVAC systems (condenser water heat recovery, ground-source heat pumps, displacement ventilation, demand-controlled ventilation, thermal storage, desiccant-based dehumidification, evaporative condensing), and electrical distribution systems (transformer efficiencies, metering) [1].

\section{DEVELOPMENT PROCESS}

The SHC-AEDG was developed by a project committee (PC) that represents a diverse group of professionals. ASHRAE, AIA, IES, USGBC, ASHE, and DOE collaborated to provide guidance and support. Members of the PC came from these partner organizations, the ASHRAE Standing Standards Project Committee 90.1, and the ASHRAE Technical Committee 9.6, Healthcare Facilities. A steering committee (SC) made up of representatives of ASHRAE, AIA, IES, USGBC, ASHE, and DOE oversaw the PC as the guide was developed. The SC assigned a timeline for the task, an energy savings goal, a target audience, space types to include, and possible topics to incorporate.

Following SC guidance, the PC developed a one-year plan for completing the document. The PC used a schedule to plan for two peer review periods that corresponded with a $65 \%$ completion draft (technical refinement review) and a $90 \%$ completion draft (final review for errors). A focus group reviewed the conceptual $35 \%$ draft. Many meetings and conference calls were also held with the full PC during the development of the guide.

\section{EVALUATION APPROACH}

The guide contains a set of energy efficiency recommendations for each of the eight DOE climate zones across the United States. The following steps describe how the energy savings potential of the guide's recommendations was determined.

\subsection{Develop "Typical" Small Hospital and Healthcare Facility Prototypes}

For building characteristics that are not specified by Standard 90.1 but that are needed to develop code-compliant baseline models, the PC chose two recently constructed healthcare facilities (a surgery center and a community hospital) as the foundation for the prototypes. Information from the construction drawings for these facilities, along with publications data, was used to determine "typical" small hospital and healthcare facility characteristics. The publications surveyed include:

- $\quad$ The 2003 Commercial Buildings Energy Consumption Survey (CBECS) [6]

- Additional data sets from the PC, including actual floor plates and space programming requirements for the community hospital and the surgery center

- The DOE Buildings Database (http://eere.buildinggreen.com)

- McGraw Hill Dodge construction data

- $\quad$ The Green Guide for Healthcare [7]

- DOE Commercial Buildings Benchmark Models [8]

- $\quad$ ASHRAE Standard 62.1-2004 [9]

- 2006 AIA Guidelines for Design and Construction of Health Care Facilities [10] 
These documents were used to develop the prototype model characteristics, including form and floor plate, plug/process loads, ventilation rates, and operating schedules. These characteristics are the same for the baseline and low-energy models, and are documented in Table 1.

Table 1. Prototype Characteristics [11]

\begin{tabular}{|c|c|c|}
\hline \multirow{2}{*}{$\begin{array}{c}\text { Building } \\
\text { Characteristic }\end{array}$} & \multicolumn{2}{|c|}{ Prototype Models } \\
\hline & Community Hospital & Surgery Center \\
\hline $\begin{array}{l}\text { Size } \\
\text { Number of floors } \\
\text { Peak number of } \\
\quad \text { occupants }\end{array}$ & $\begin{array}{c}65,000 \mathrm{ft}^{2} \\
1 \\
675\end{array}$ & $\begin{array}{c}41,000 \mathrm{ft}^{2} \\
3 \\
414\end{array}$ \\
\hline $\begin{array}{l}\text { Constructions } \\
\text { WWR }\end{array}$ & $\begin{array}{c}\text { Steel-framed wall } \\
\text { Roof with insulation } \\
\text { entirely above deck } \\
26 \%\end{array}$ & $\begin{array}{c}\text { Steel-framed wall } \\
\text { Roof with insulation } \\
\text { entirely above deck } \\
20 \%\end{array}$ \\
\hline $\begin{array}{l}\text { Occupancy } \\
\text { Whole-building } \\
\text { weighted average } \\
\text { peak plug loads } \\
\end{array}$ & $\begin{array}{l}\text { Fully occupied during the day } \\
\text { Partially occupied at night } \\
2.1 \mathrm{~W} / \mathrm{ft}^{2}\end{array}$ & $\begin{array}{c}\text { Fully occupied during the day } \\
\text { Vacant at night } \\
1.8 \mathrm{~W} / \mathrm{ft}^{2}\end{array}$ \\
\hline $\begin{array}{l}\text { Percent conditioned } \\
\text { HVAC system types }\end{array}$ & $\begin{array}{c}\text { Fully heated and cooled } \\
\text { Baseline: Packaged variable air } \\
\text { volume system (PVAV) with } \\
\text { direct expansion (DX) cooling, } \\
\text { water boiler heating } \\
\text { Low-energy: PVAV with } \\
\text { DX cooling or air-cooled } \\
\text { chiller or water-cooled chiller, } \\
\text { water boiler heating }\end{array}$ & $\begin{array}{c}\text { Fully heated and cooled } \\
\text { Baseline: PVAV with DX cooling, } \\
\text { water boiler heating } \\
\text { Low-energy: PVAV with DX } \\
\text { cooling or air-cooled chiller } \\
\text { or water-cooled chiller, } \\
\text { water boiler heating }\end{array}$ \\
\hline
\end{tabular}

\subsection{Create Baseline Models from the Prototypes that are Minimally Code Compliant for Standard 90.1-1999}

The baseline models for the small hospital and healthcare facility were developed by applying the applicable criteria in Standard 90.1-1999 to the prototype models. The baseline small hospital and healthcare facility energy modeling assumptions obtained from Standard 90.1-1999 include the envelope characteristics, building lighting loads, HVAC equipment efficiency, operation, control, sizing, fan power assumptions, and SWH efficiency. 


\subsection{Create the Low-Energy Models Based on the Recommended Energy Efficiency Technologies in the Guide}

The final recommendations were determined based on an iterative process using the PC's expertise and results from modeling the recommendations. To quantify the potential energy savings from the final recommended energy efficiency measures, the low-energy building models were simulated by implementing the following energy efficiency technologies. The energy efficiency measures that were applied to all climate zones and included in the energy saving calculation are:

- Enhanced building opaque envelope insulation

- $\quad$ Enhanced window glazing with overhangs

- $\quad$ Reduced lighting power density (LPD) and occupancy control

- Daylighting in staff areas (exam rooms, nurse stations, offices, corridors) and public spaces (waiting, reception)

- $\quad$ Higher efficiency HVAC equipment

- $\quad$ High-efficiency SWH

\subsection{Verify 30\% Energy Savings Across the Various HVAC System Types Over the Eight U.S. Climate Zones}

EnergyPlus ${ }^{12}$ was used to perform building energy simulation analysis to assess and quantify the energy savings potential of the guide's recommendations. Two sets of simulations were run for each prototype: the first meets the minimum requirements of Standard 90.1-1999; the second uses the recommendations in the guide to achieve 30\% energy savings. For each low-energy design, three cooling equipment types were modeled: a package rooftop system with direct expansion (DX) cooling, a packaged rooftop system with a central air-cooled chiller, and a packaged rooftop system with a central water-cooled chiller. The recommendations result in greater than $30 \%$ energy savings in all climate zones for each prototype within the range of cooling system types.

The flowchart in Figure 1 shows the evaluation approach.

\section{MODELING METHODS}

\subsection{Climate Zones}

The guide contains a unique set of energy efficiency recommendations for a range of climate zones. The common set of climate zones includes eight zones covering the entire United States (see Figure 2). Climate zones are categorized by heating degree days and cooling degree days, and range from the very hot zone 1 to the very cold zone 8 . Some climate zones are divided into subzones based on humidity levels. Humid subzones are "A" zones, dry subzones are "B" zones, and marine subzones are "C" zones. The combination of climate zones 1 through 8 , along with their respective subzones "A," "B," and "C," create 15 unique climate zones.

Fifteen specific climate locations (cities) were selected as being most representative of each subzone, as shown in the list. To determine energy savings, Typical Meteorological Year 2 weather files for each location were used to simulate the baseline and low-energy models. 


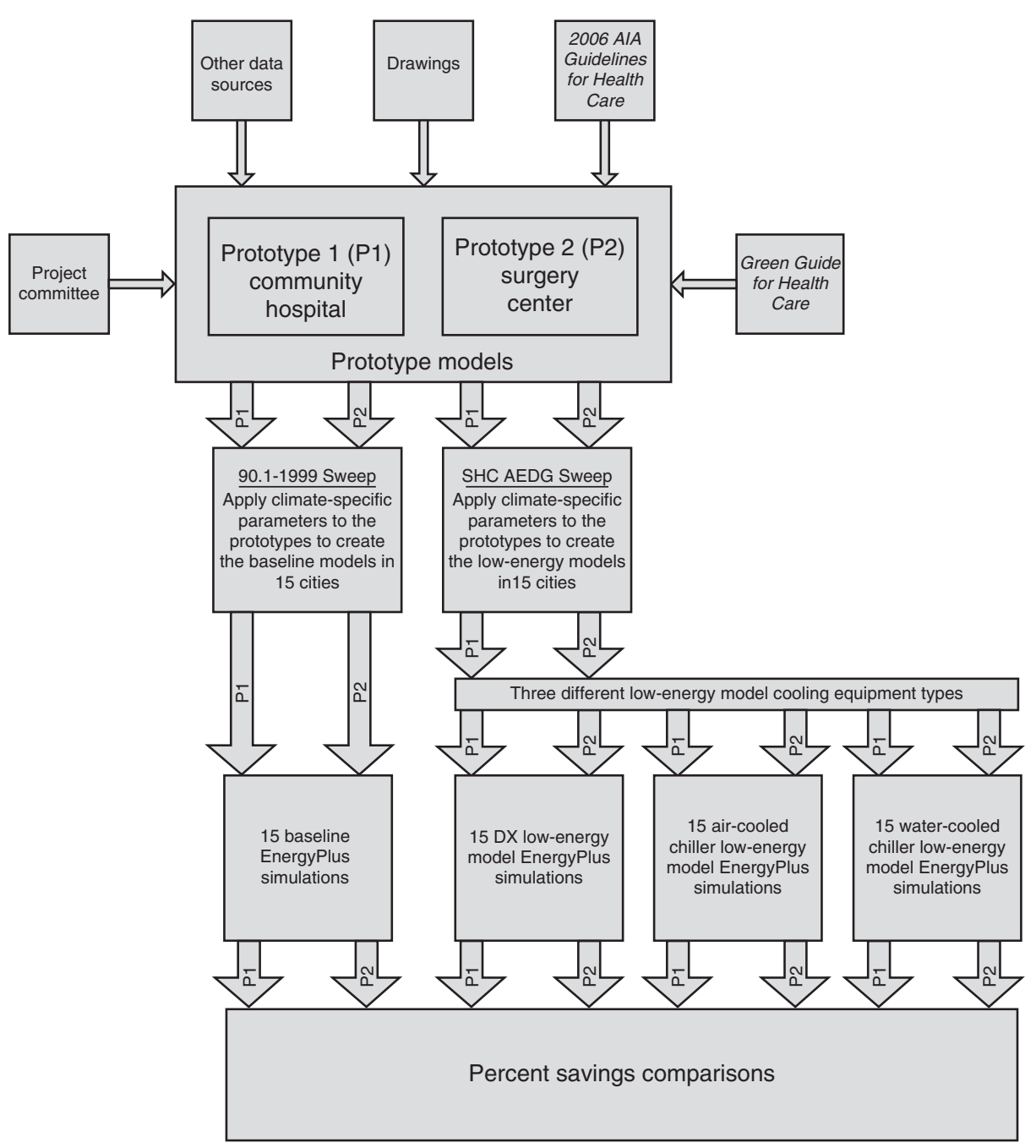

Figure 1. Evaluation Approach Flowchart [11].

- Zone 1: Miami, Florida (hot, humid)

- Zone 2A: Houston, Texas (hot, humid)

- Zone 2B: Phoenix, Arizona (hot, dry)

- Zone 3A: Memphis, Tennessee (hot, humid)

- Zone 3B: El Paso, Texas (hot, dry)

- Zone 3C: San Francisco, California (marine)

- Zone 4A: Baltimore, Maryland (mild, humid)

- Zone 4B: Albuquerque, New Mexico (mild, dry) 


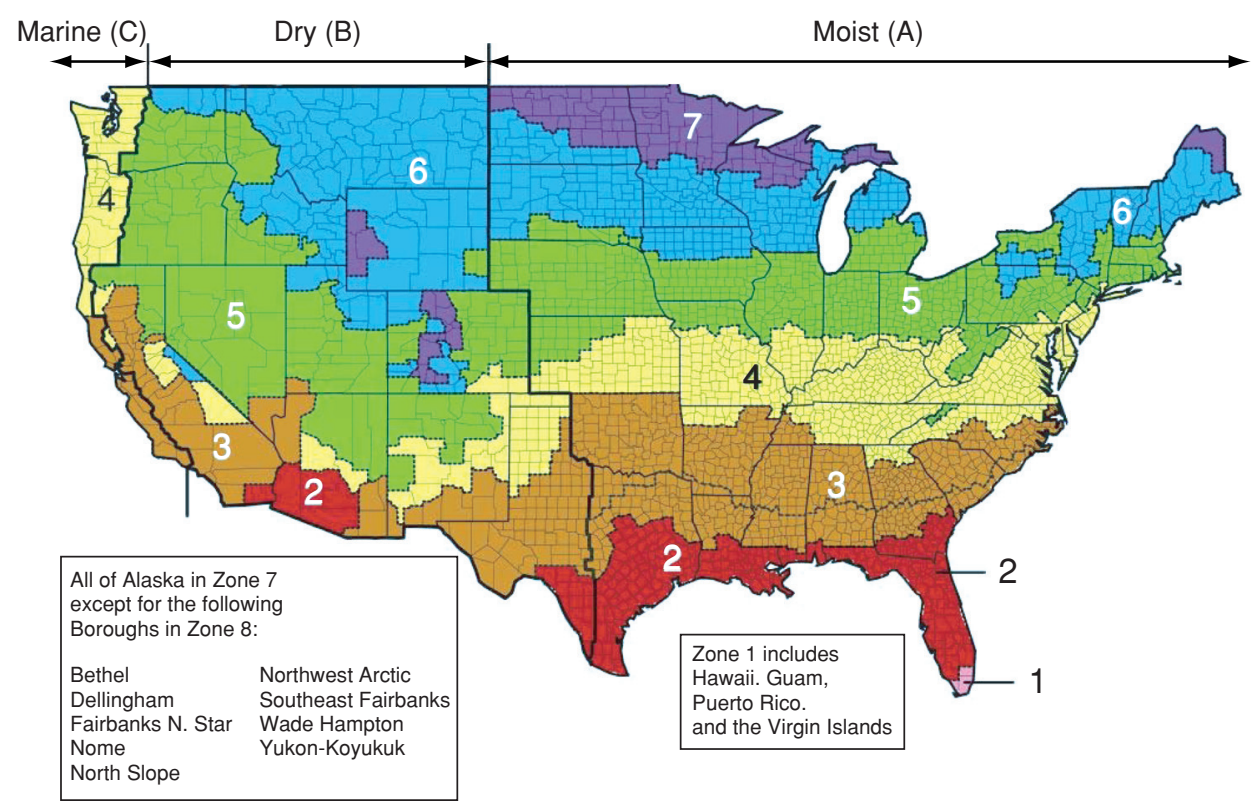

Figure 2. Climate Zones and Representative Cities [11].

- Zone 4C: Seattle, Washington (marine)

- Zone 5A: Chicago, Illinois (cold, humid)

- Zone 5B: Boise, Idaho (cold, dry)

- Zone 6A: Burlington, Vermont (cold, humid)

- Zone 6B: Helena, Montana (cold, dry)

- Zone 7: Duluth, Minnesota (very cold)

- Zone 8: Fairbanks, Alaska (extremely cold)

\subsection{Analysis Platform}

EnergyPlus version 3.1 was used to complete the energy simulations [12]. EnergyPlus is the contemporary DOE tool that accounts for the complicated interactions between climate, internal gains, building form and fabric, HVAC systems, and renewable energy systems. Alongside EnergyPlus, Opt-E-Plus [13], a software research tool that integrates with EnergyPlus, was used to aid in this analysis. Opt-E-Plus was developed by the commercial buildings research group at NREL and was used to create and manage the EnergyPlus input files.

The main analysis started with 8 "seed" EnergyPlus input files (1 baseline and 3 lowenergy models for the 2 prototypes). Opt-E-Plus was then used to sweep these input files across the 15 climate zones, generating 120 input files. Interim analysis included sweeping 16 other "seed" EnergyPlus input files across the 15 climate zones to create 240 separate input files, for a total of 360 individual EnergyPlus input files. During this 
sweep, Opt-E-Plus applied climate zone-specific AEDG-SHC recommendations (such as roof insulation values) to each input file. When interfaced with a Linux supercomputer, Opt-E-Plus was able to complete approximately 1,440 linear simulation hours in only 12 clock hours.

The results were then analyzed to determine the energy savings over the codecompliant baseline. If the $30 \%$ savings target was not met for each simulation, changes were made to the recommendations and the analysis restarted from the beginning. These "seed" input files were continuously updated based on the results of the previous simulation iteration as the project progressed and were reswept numerous times. The automation of certain portions of this iterative process with Opt-E-Plus made this project possible in the allotted time frame. Ultimately, the $30 \%$ savings goal was achieved for each climate zone.

\section{RECOMMENDATIONS}

The guide makes recommendations for enhanced efficiency in several building systems to meet the 30\% savings target. To further illustrate the impacts of these recommendations, Table 2 shows the comparison between Standard 90.1-1999 and the climate-specific recommendations for climate zone 5A (Chicago). The recommendations presented are either minimum or maximum values. Minimum values include:

- $\quad$ R-values (continuous insulation [c.i] where noted)

- Mean lumens/watt (MLPW)

- Solar Reflectance Index (SRI)

- $\quad$ Energy efficiency ratio (EER)

- Integrated energy efficiency ratio (IEER)

- Integrated part-load value (IPLV)

- $\quad$ Coefficient of performance (COP)

- Effectiveness

- $\quad$ Combustion efficiency $\left(\mathrm{E}_{\mathrm{c}}\right)$

- Thermal efficiency $\left(\mathrm{E}_{\mathrm{t}}\right)$

- $\quad$ Energy factor $(\mathrm{EF})$

- Duct or pipe insulation thickness

Maximum values include:

- Fenestration insulation (U-factors)

- Fenestration solar heat gain coefficient (SHGC)

- Total fenestration to gross wall area ratio (WWR)

- $\quad$ Lighting power density (LPD)

- $\quad$ Fan brake horsepower (bhp)

- $\quad$ Fan input power per cfm of supply airflow (W/cfm)

Table 2 highlights some recommendations; although examples from only one climate zone are shown here, the guide contains recommendations for all eight climate zones. 


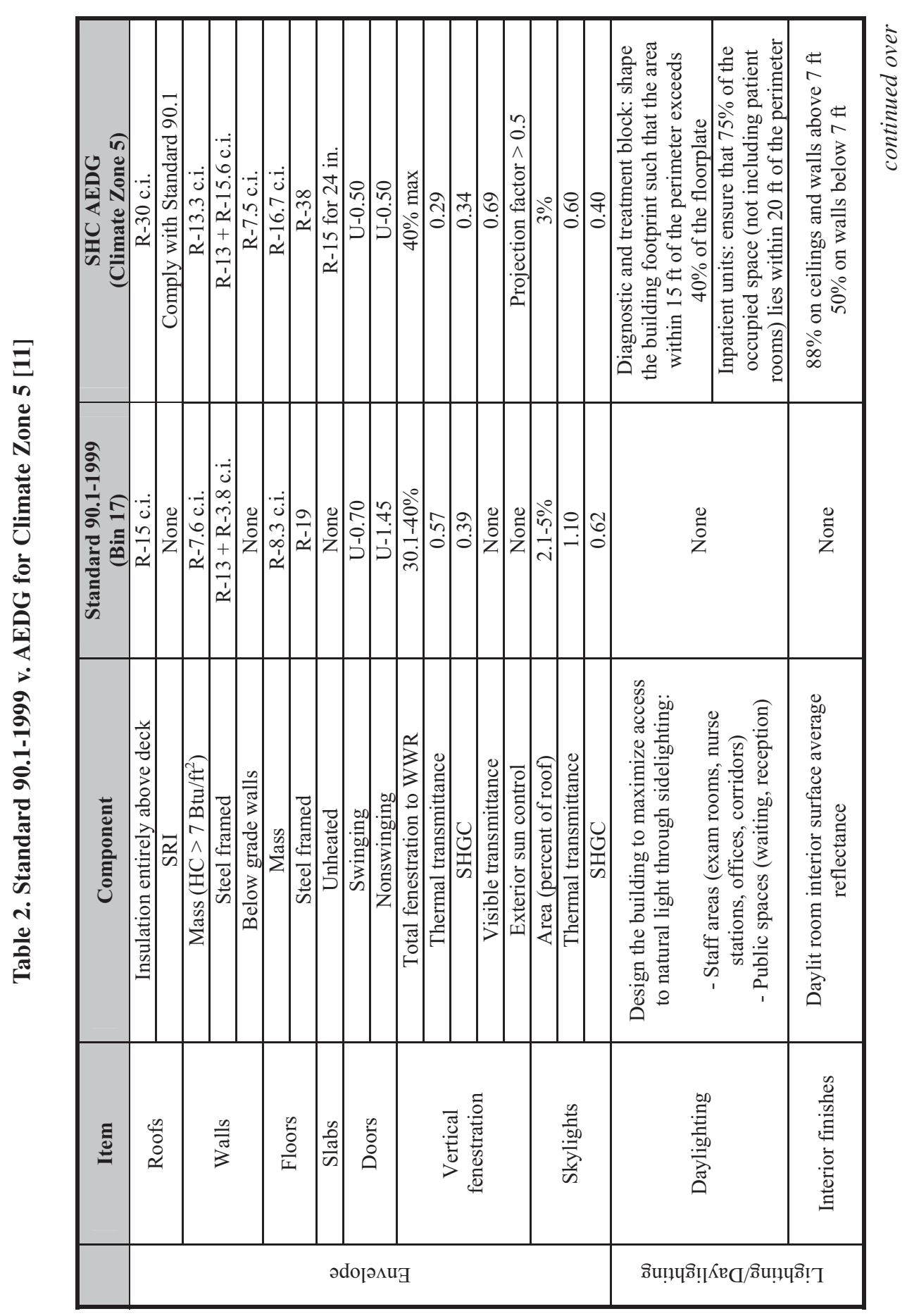




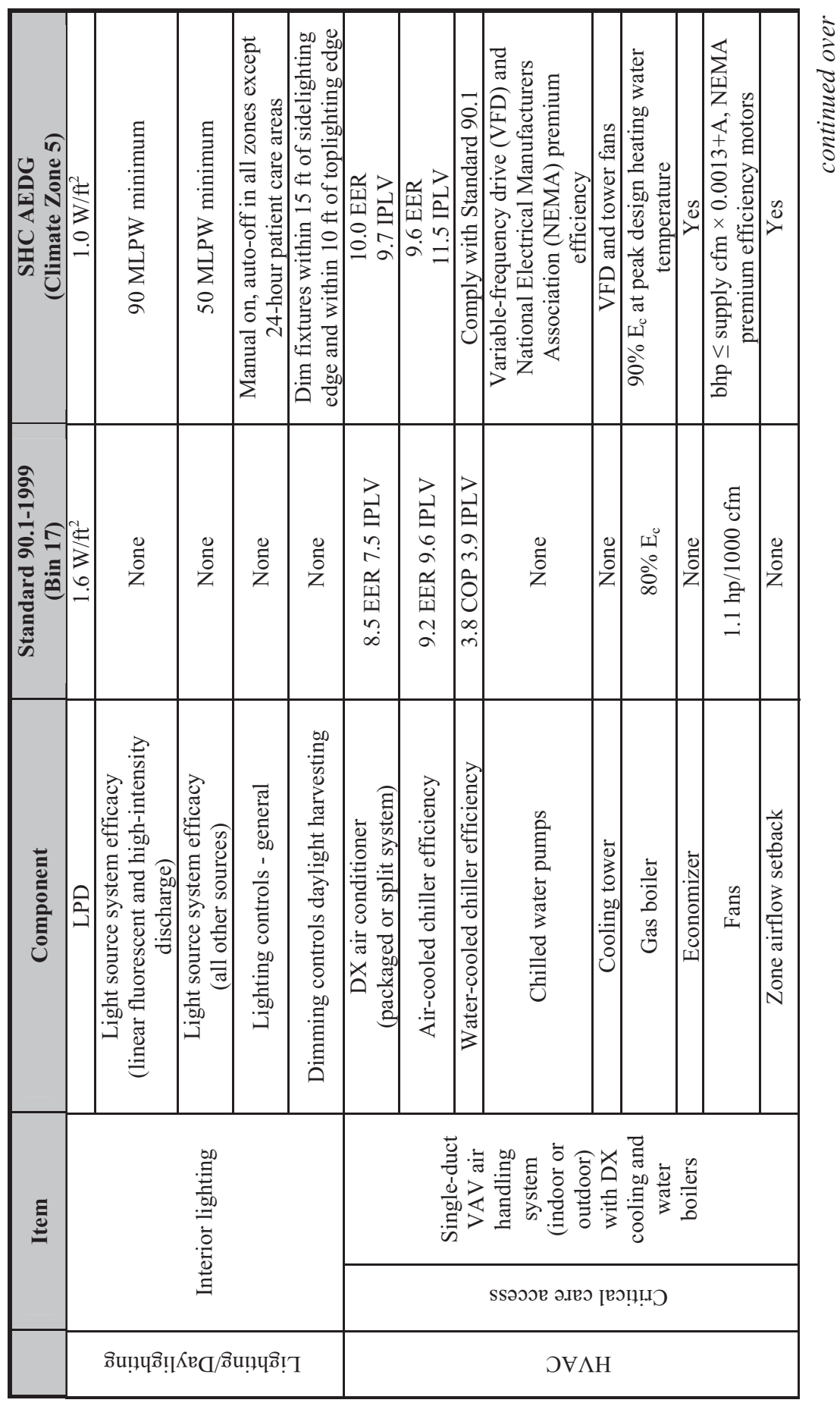




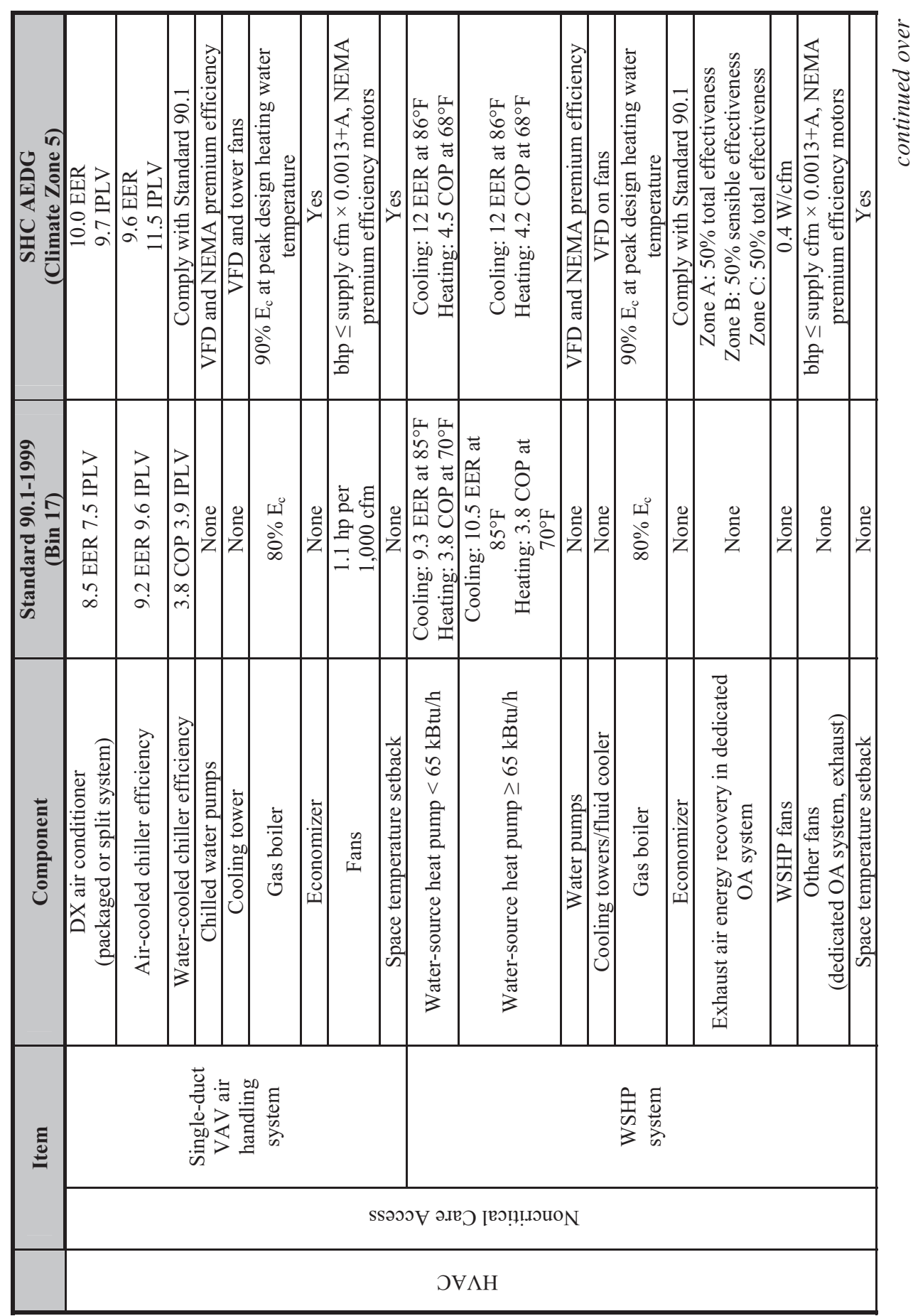




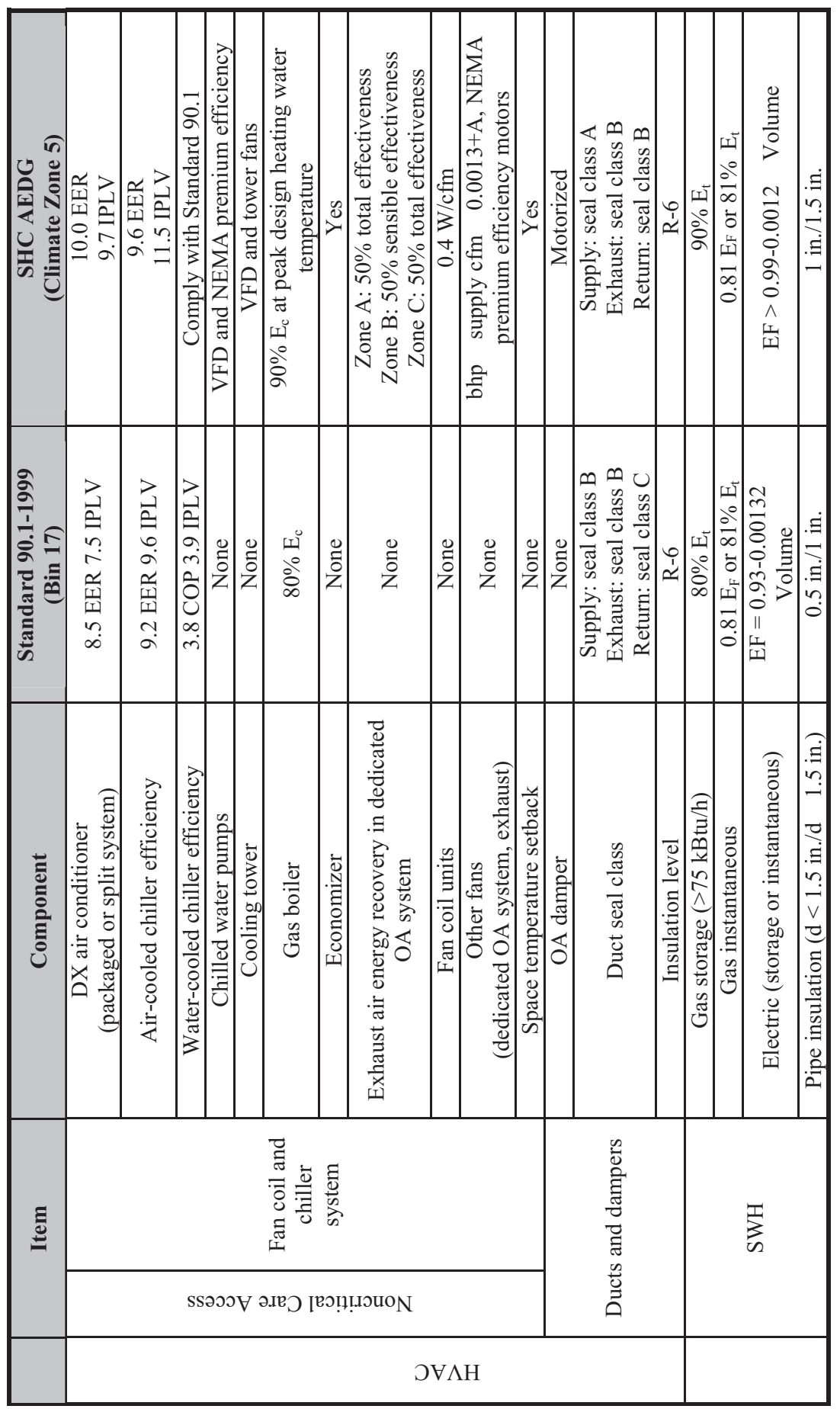


A review of the recommendations for all climate zones indicates how climate affects specific differences between low-energy and baseline models. For example, the recommended increase in roof insulation is greater in cold climates than in hot climates, reflecting the greater potential for extra insulation to save energy in colder regions. Mass wall insulation nearly doubles in hot and cold climates compared to Standard 90.1-1999; steel-framed walls add continuous insulation in hot climates and significantly increase in R-value in cold climates. Slab insulation increases over Standard 90.1-1999 in cold climates only, again reflecting the greater impact of insulation in cold climates. Vertical glazing thermal transmittance changes fairly substantially in hot climates because it switches from single to double glazing, but the value changes less dramatically in cold climates. SHGCs change slightly in hot and cold climates. Adding window overhangs with a projection factor greater than 0.5 was recommended for all climate zones.

The concept for improving the building envelope was based around the fact that most small healthcare facilities use constant-volume reheat systems to handle the space conditioning needs. These systems have traditionally been common in such facilities because they can independently control temperature and humidity and maintain space pressurization requirements. The roof, wall insulation, and window performance was increased, which reduced the constant-volume airflow needs and associated reheat. The envelope thermal performance was increased to the point that the reduced airflow needs meet the code-required minimum values. This saves on fan power and reheat energy, and smaller constant-volume systems can save capital costs with smaller air systems and reduced cooling capacity.

The daylighting recommendations include designing the building to maximize access to natural light through sidelighting in staff areas (exam rooms, nurse stations, offices, corridors) and public spaces (waiting, reception), along with daylighting controls. General LPDs were reduced $37.5 \%$ in this guide compared to Standard 90.11999 , representing a large proportion of the total energy savings.

HVAC cooling efficiencies improved $15 \%$ in this guide compared to Standard 90.11999 in all climates zones except 6, 7, and 8, where they remained unchanged from Standard 90.1-1999 because the cooling energy represented a small portion of the whole-building energy use. Because high air change rates and humidity control are required in many space types, the constant-volume reheat HVAC systems that have traditionally been used in these facilities use a lot of energy for reheat. The baseline energy modeling shows that reheat represents more than $20 \%$ of the total energy use in all climate zones. Thus, high-efficiency condensing boilers are recommended for all climate zones because of the significant reheat energy required to maintain airflow requirements and humidity control in all locations. The SWH recommendations indicate the value of using either high-efficiency or point-of-use water heaters to reduce water heating energy use.

\section{ENERGY SAVINGS RESULTS}

Annual hourly simulations of two prototype buildings established the energy savings results from the application of the guide. One prototype building was the $65,000 \mathrm{ft}^{2}$ 
$\left(6,040 \mathrm{~m}^{2}\right)$ community hospital; the other was a 41,000 $\mathrm{ft}^{2}\left(3,810 \mathrm{~m}^{2}\right)$ surgery center. Both prototypes were simulated in all 15 climate locations, representing humidity subzones for the eight climate zones depicted in the guide and the standard.

The results of the simulations are indicated in Figure 3, showing the energy savings compared to the baseline for the community hospital and the surgery center.

All locations achieved the $30 \%$ savings for the community hospital and the surgery center. In general, the community hospital outperformed the surgery center in most climate locations because of its continuous (24-hour) operation. With lower lighting levels, additional heating energy was necessary to compensate for the heating typically gained from lighting power sources. However, this was more than offset by the cooling load reduction associated with lower lighting levels.

Complete results of the prototype facility simulations are presented in the Technical Support Document: Development of the Advanced Energy Design Guide for Small Hospitals and Healthcare Facilities, available at http://www.nrel.gov/docs/fylOosti/ 46314.pdf [11].

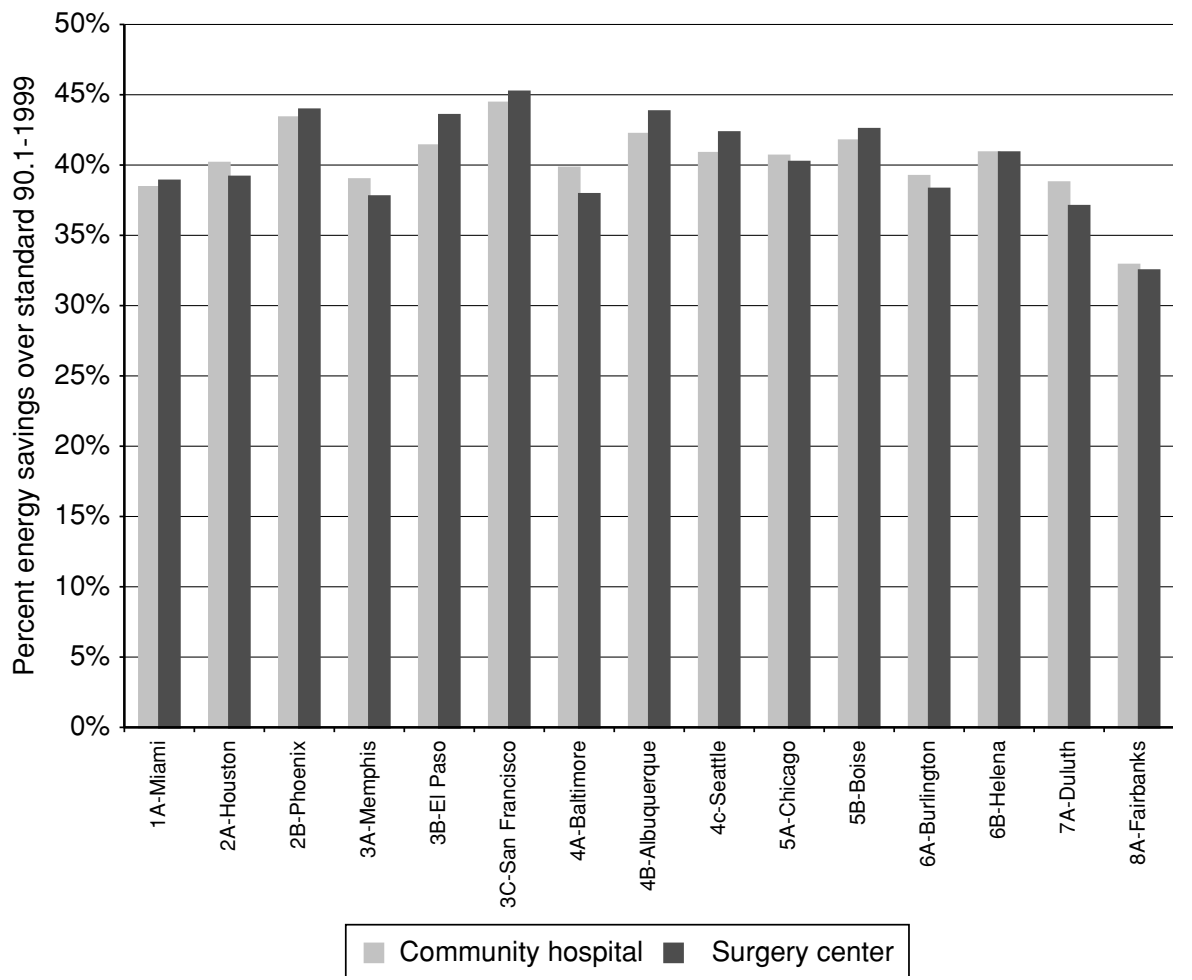

Figure 3. Percent Savings for the PVAV with DX Cooling Models. 


\section{BUNDLED ENERGY EFFICIENCY MEASURE ANALYSIS}

During the modeling process, a baseline model and a low-energy model were created and compared to provide the percent savings numbers. The low-energy model was created by starting with the prototype model and applying as many guide recommendations as possible. However, it is difficult to determine which recommendations provide the most energy savings because they are all applied to the prototype model in a single operation. To better understand how each recommendation affects energy performance, a study was performed in which each guide recommendation was incrementally and aggregately applied until the low-energy model was achieved. This study was termed $a$ bundled energy efficiency measure analysis and consisted of seven steps: (1) apply the envelope efficiency measures, which included adding overhangs to the south windows, adding skylights to the surgery center, and upgrading the building materials in accordance with the guide recommendations; (2) reduce space-by-space LPD; (3) add daylighting controls to applicable zones; (4) reduce fan pressure drop and increase fan efficiencies; (5) improve boiler and SWH efficiencies; (6) improve DX cooling efficiencies; and (7) implement a zone airflow setback strategy in which the HVAC terminal boxes mimicked constant air volume boxes during occupied times and VAV

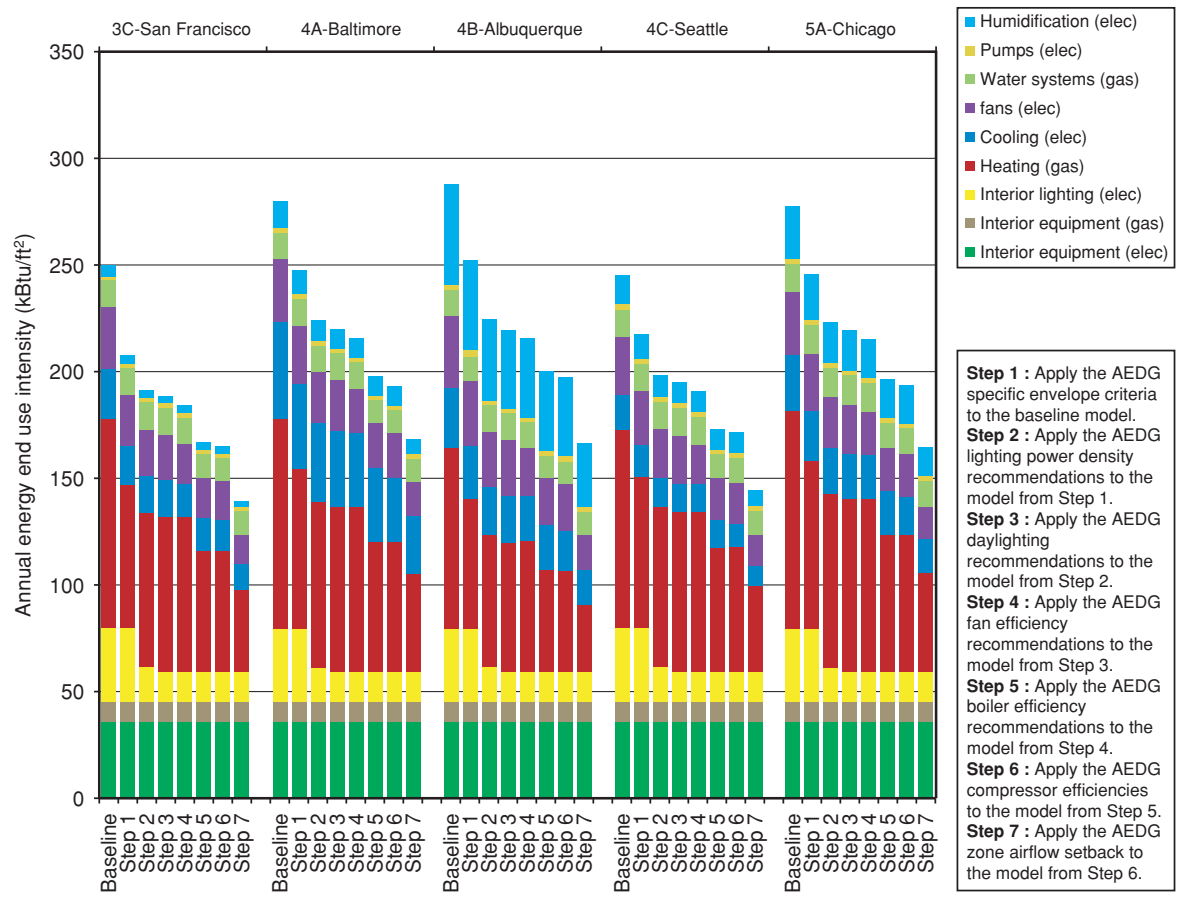

Figure 4. Community Hospital Bundled Energy Efficiency Measure Analysis Results for Climate Zones 1A through 3B. 


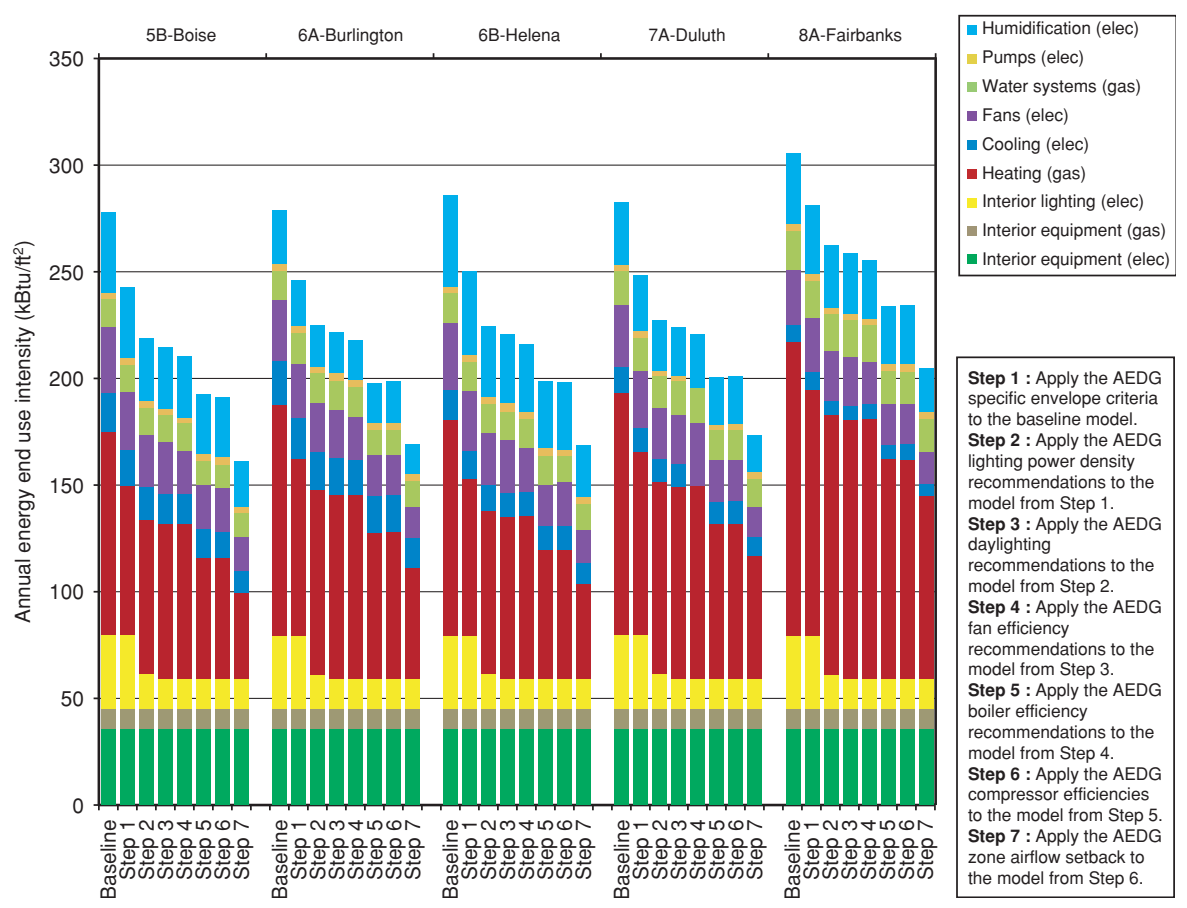

Figure 5. Community Hospital Bundled Energy Efficiency Measure Analysis Results for Climate Zones 3C through 5A.

boxes during unoccupied times. The bundled energy efficiency analysis energy results by end use for the community hospital are shown in Figure 4 (climate zones $1 \mathrm{~A}$ through 3B), Figure 5 (climate zones 3C through 5A), and Figure 6 (climate zones 5B through 8A).

The results of this analysis show the biggest energy savers are the LPD reductions and the implementation of a zone airflow setback. Colder climates benefited more from the improved boiler efficiencies; hotter climates benefited more from improved cooling efficiencies.

\section{SUMMARY}

As with the previous guides in the series, the SHC-AEDG provides a simple, easy-touse guide to help the building designer, contractor, and owner identify a clear prescriptive path to $30 \%$ energy savings over Standard 90.1-1999. In many ways, the SHC-AEDG is a simple interface to a complex analysis performed using EnergyPlus. The combination of a set of recommendations contained on a single page, along with numerous how-to tips to help the construction team complete the project successfully, should result in increased energy efficiency in new buildings. Case studies of actual small healthcare applications add to the comprehension of energy efficiency 


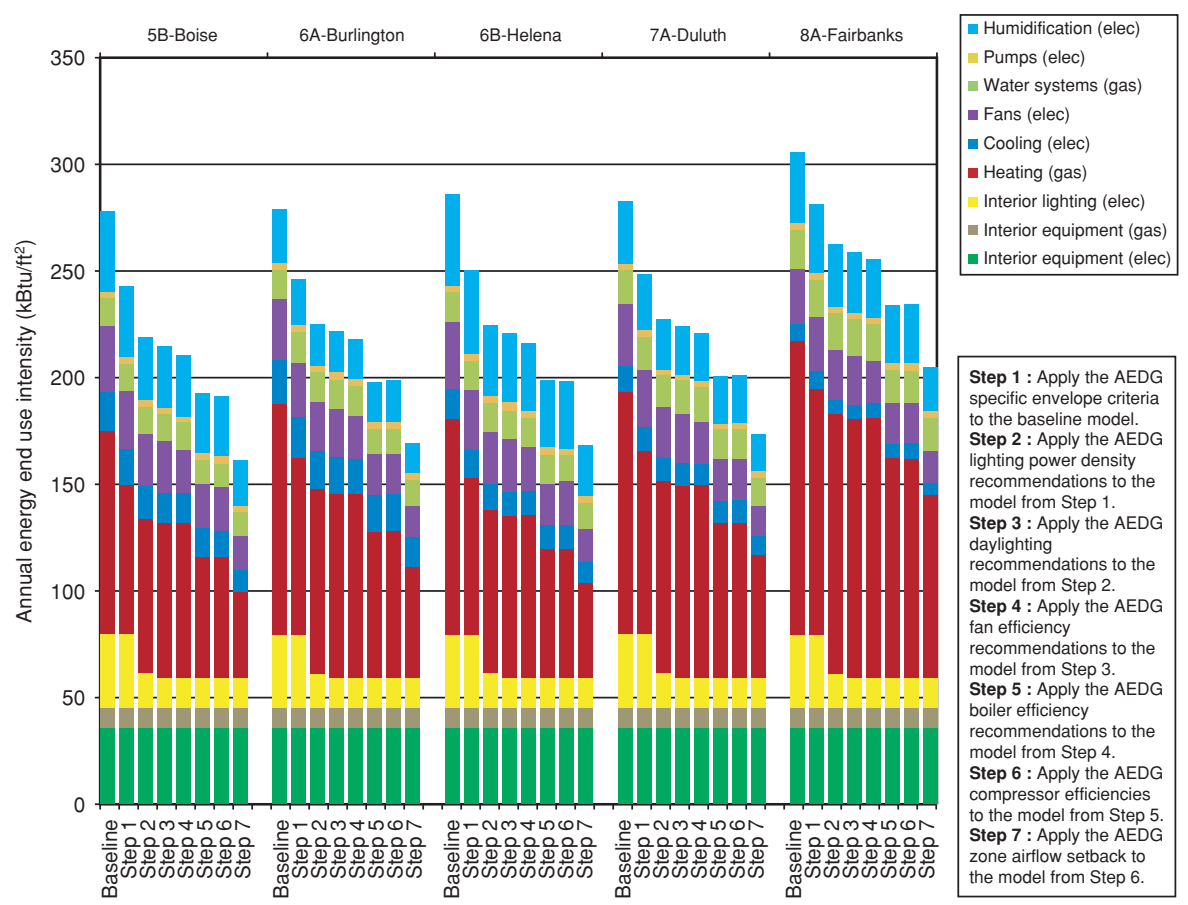

Figure 6. Community Hospital Bundled Energy Efficiency Measure Analysis Results for Climate Zones 5B through 8A.

opportunities. The SHC-AEDG is available for print purchase or as a free download from http://www.ashrae.org/aedg.

The ultimate goal of the Advanced Energy Design Guide partner organizations is to achieve net-zero energy buildings, and the $30 \%$ savings guides represent the first step in reaching this goal. The SHC-AEDG marks the last in the series of $30 \%$ savings design guides. This guide has furthered similar work in the healthcare energy efficiency field, as it set the stage for developing a large hospital best practices guide and is used in planning the next series of 50\% savings Advanced Energy Design Guides. Also, U.S. government healthcare facilities are starting to use the guide to meet EPAct 2005 energy efficiency requirements.

\section{ACKNOWLEDGEMENTS}

The authors would like to thank all the members of the PC for their diligence, creativity, and willingness to support the creation of the guide. This project would not have been possible without financial contributions from DOE, through Drury Crawley and Pat LeDonne of the Building Technologies Program. Additional thanks to the ASHRAE staff, whose direction, guidance, organizational skills, and dedication enabled timely completion of the guide. 


\section{REFERENCES}

[1] ASHRAE, AIA, IES, USGBC, DOE, Advanced Energy Design Guide for Small Hospitals and Healthcare Facilities, American Society of Heating, Refrigerating and Air-Conditioning Engineers, Atlanta, 2009.

[2] ANSI/ASHRAE/IESNA, Standard 90.1-1999 Energy Standard for Buildings except Low-Rise Residential Buildings, American Society of Heating, Refrigerating and Air-Conditioning Engineers, Atlanta, 1999.

[3] Torcellini, P., Pless, S., Deru, M., Crawley, D., Zero Energy Buildings: A Critical Look at the Definition, ACEEE Summer Study on Energy Efficiency in Buildings, Golden, National Renewable Energy Laboratory, 2006.

[4] ASHRAE, AIA, IESNA, NBI, DOE, Advanced Energy Design Guide for Small Office Buildings, American Society of Heating, Refrigerating and Air-Conditioning Engineers, Atlanta, 2000.

[5] Colliver, D.G. and Jarnagin, R.E., Savings 30\% Over Standard 90.1-1999: Advanced Energy Design Guide for Small Office Buildings, ASHRAE Journal, 2005, 47 (3), 22-27.

[6] EIA, 2003 Commercial Buildings Energy Consumption Survey, EIA, Washington D.C., 2003, Available from http://eia.doe.gov/emeu/cbecs/cbecs2003/introduction.html.

[7] GGHC, Green Guide for Health Care: Best Practices for Creating High Performance Healing Environments, Version 2.2, http://www.gghc.org, August 2009.

[8] Torcellini et al., DOE Commercial Building Benchmark Models: Preprint, National Renewable Energy Laboratory, Golden, NREL Report No. CP-550-43291, 2008.

[9] ASHRAE, Standard 62.1-2004 Ventilation for Acceptable Indoor Air Quality, American Society of Heating, Refrigerating and Air-Conditioning Engineers, Atlanta, 2004.

[10] AIA, Guidelines for Design and Construction of Health Care Facilities, American Institute of Architects, Washington D.C., 2006.

[11] Pless, S., Torcellini, P., Doebber, I., Bonnema, E., Technical Support Document: Development of the Advanced Energy Design Guide for Small Hospitals and Healthcare Facilities-30\% Energy Savings. National Renewable Energy Laboratory, Golden, NREL Report No. TP-550-46314, 2010.

[12] DOE, EnergyPlus Simulation Software, Version 3.1, U.S. Department of Energy, Washington D.C., http://www.energyplus.gov, 2009.

[13] “Opt-E-Plus Software for Commercial Building Optimization,” NREL/FS-550-45620. Golden, CO: National Renewable Energy Laboratory. http://www.nrel.gov/docs/fy10osti/45620.pdf, 2010. 



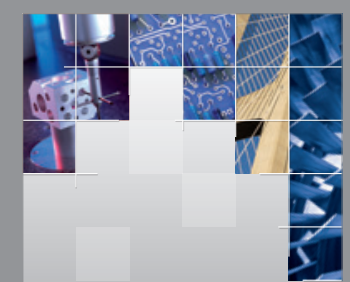

\section{Enfincering}
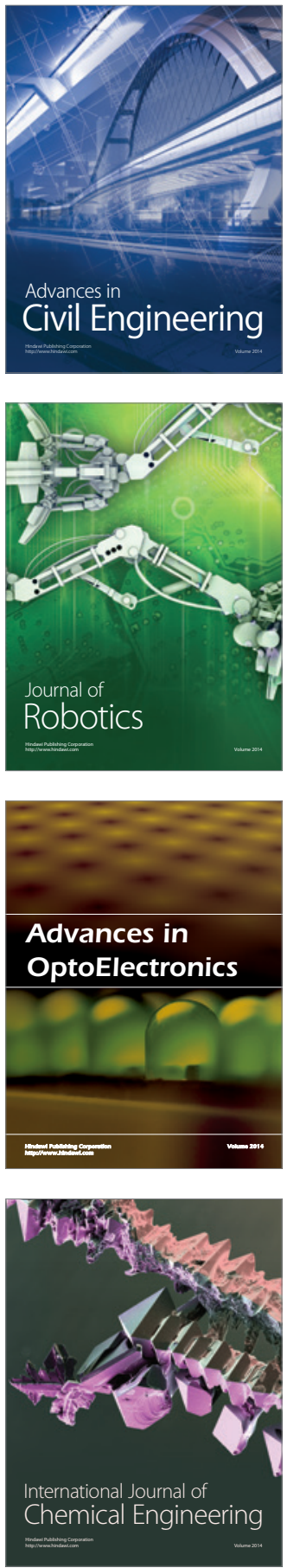

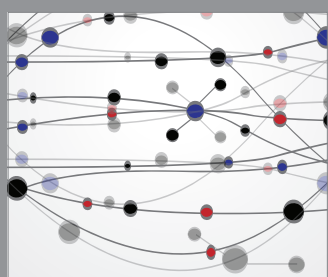

The Scientific World Journal

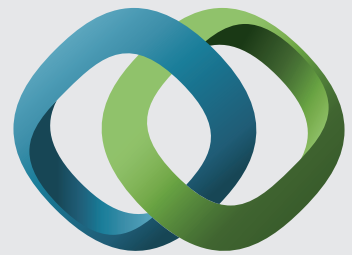

\section{Hindawi}

Submit your manuscripts at

http://www.hindawi.com
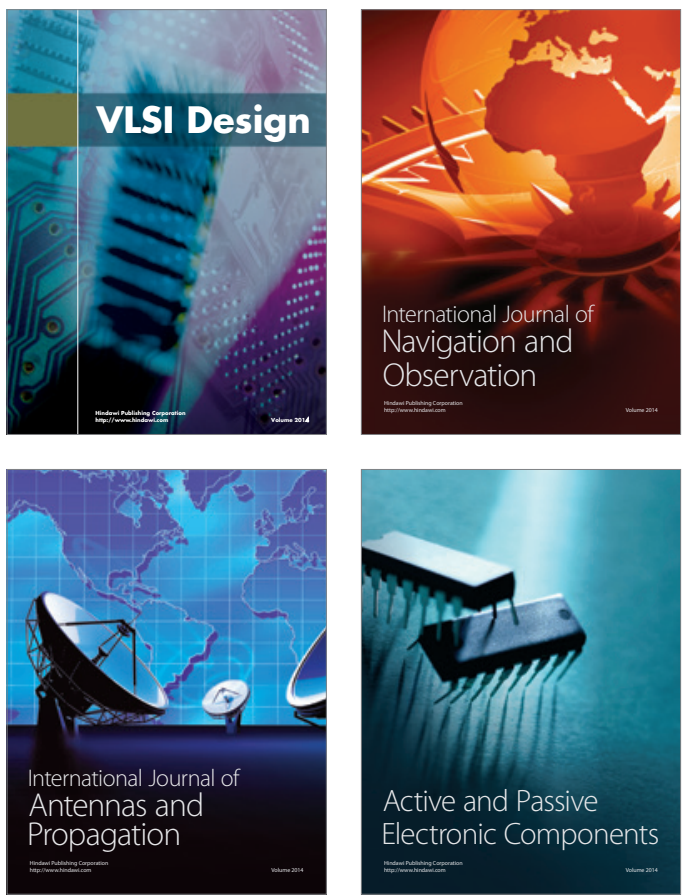
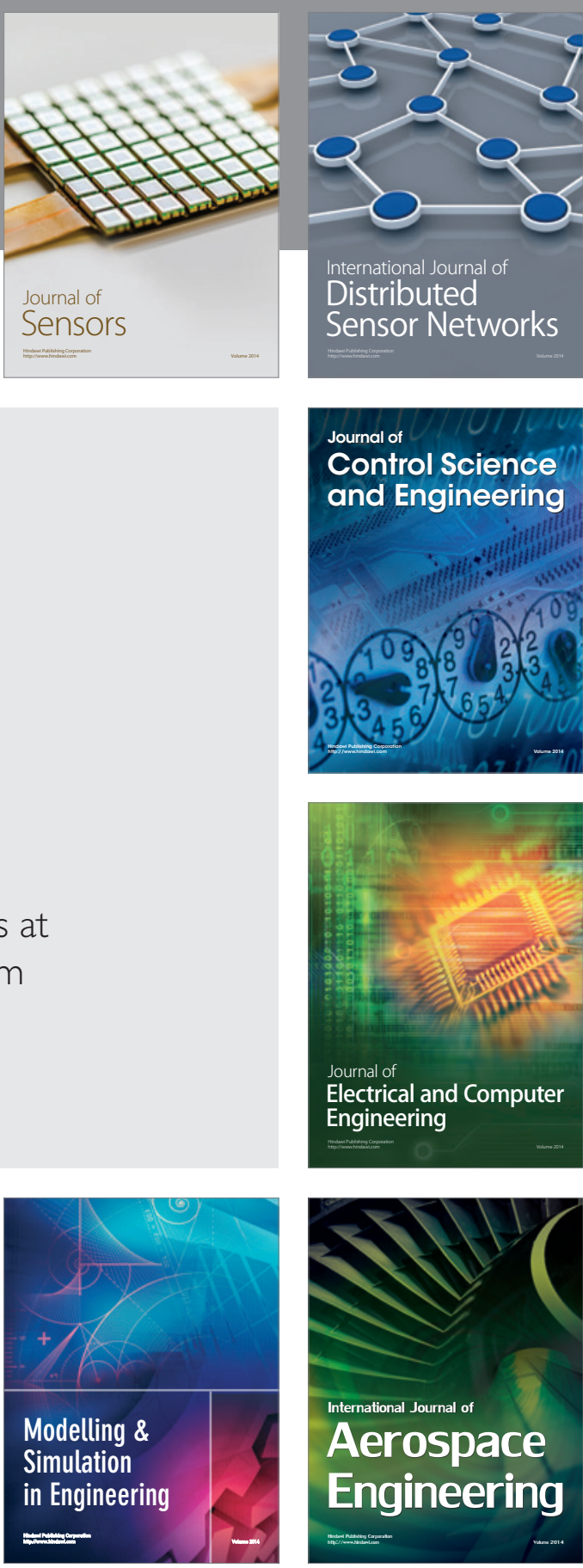

International Journal of

Distributed

Sensor Networks

Journal of

Control Science

and Engineering
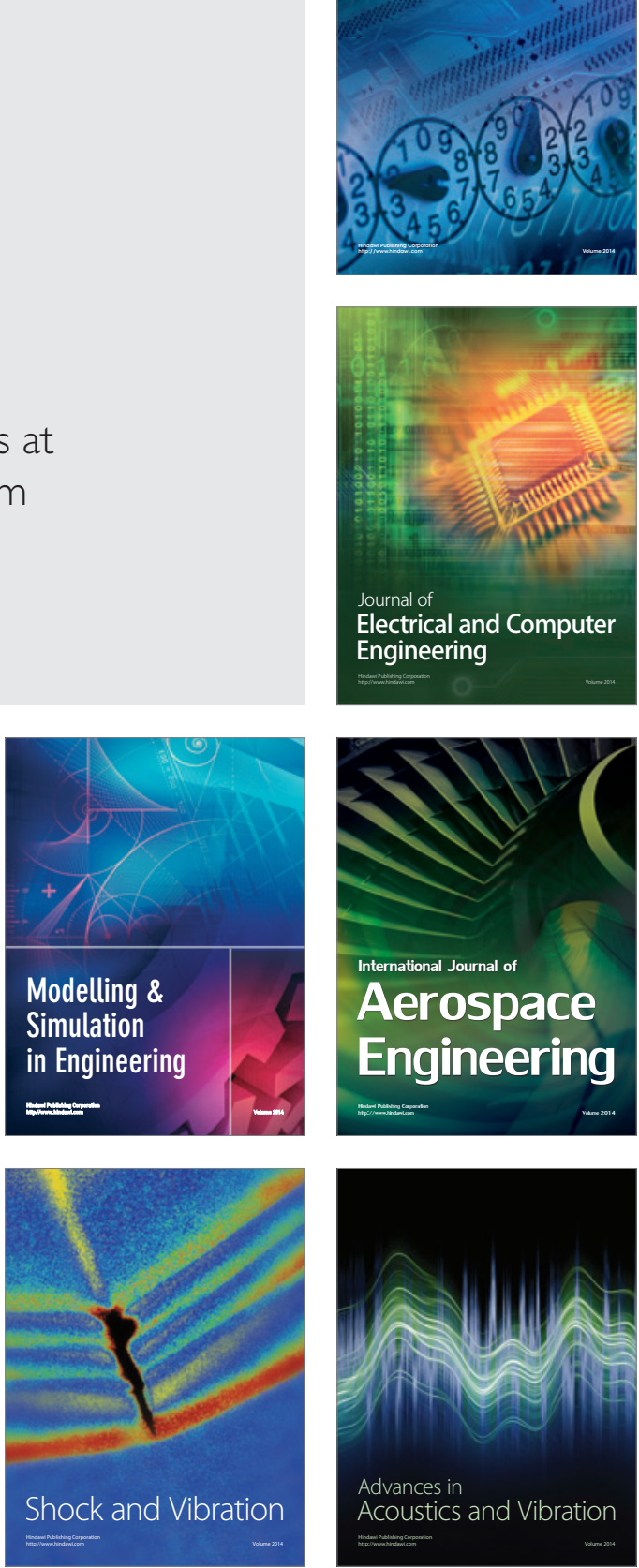